\title{
Anti-Oral Microbial Activity and Anti-Inflammatory Effects of Rosmarinic Acid in Lipopolysaccharide-Stimulated MC3T3-E1 Osteoblastic Cells on a Titanium Surface
}

\author{
Moon-Jin Jeong ${ }^{1}$, Do-Seon $\mathrm{Lim}^{2}$, Kyungwon $\mathrm{Heo}^{1}$, and Soon-Jeong Jeong ${ }^{3, \dagger}$ \\ ${ }^{1}$ Department of Oral Histology and Developmental Biology, School of Dentistry, Chosun University, Gwangju \\ 61452, ${ }^{2}$ Department of Dental Hygiene, Graduate School of Public Health Science, Eulji University, Seongnam \\ 13135, ${ }^{3}$ Department of Dental Hygiene \& Institute of Basic Science for Well-Aging, Youngsan University, \\ Yangsan 50510, Korea
}

\begin{abstract}
Background: The purpose of this study was to investigate the anti-oral microbial activity and anti-inflammatory effects of rosmarinic acid (RA) in lipopolysaccharide (LPS)-stimulated MC3T3-E1 osteoblastic cells on a titanium (Ti) surface during osseointegration, and to confirm the possibility of using RA as a safe natural substance for the control of peri-implantitis (PI) in Ti-based dental implants.

Methods: A disk diffusion test was conducted to confirm the antimicrobial activity of RA against oral microorganisms. In order to confirm the anti-inflammatory effects of RA, inflammatory conditions were induced with $100 \mathrm{ng} / \mathrm{ml}$ of LPS in MC3T3-E1 osteoblastic cells on the Ti surface treated with or without $14 \mu \mathrm{g} / \mathrm{ml}$ of RA. The production of nitric oxide (NO) and prostaglandin E2 (PGE $)$ in LPS-stimulated MC3T3-E1 osteoblastic cells on the Ti surface was confirmed using an NO assay kit and PGE $E_{2}$ enzyme-linked immunosorbent assay kit. Reverse transcription polymerase chain reaction and western blot analysis were performed to confirm the expression of interleukin (IL) $-1 \beta$ and tumor necrosis factor (TNF) $-\alpha$ in total RNA and protein.

Results: RA showed weak antimicrobial effects against Streptococcus mutans and Escherichia coli, but no antimicrobial activity against the bacteria Aggregatibacter actinomycetemcomitans and the fungus Candida albicans. RA reduced the production of pro-inflammatory mediators, NO and PGE 2 , and proinflammatory cytokines, TNF- $\alpha$ and IL-1 $\beta$, in LPS-stimulated MC3T3-E1 osteoblastic cells on the Ti surface at the protein and mRNA levels.

Conclusion: RA not only has anti-oral microbial activity, but also anti-inflammatory effects in LPS-stimulated MC3T3-E1 osteoblasts on the Ti surface, therefore, it can be used as a safe functional substance derived from plants for the prevention and control of PI for successful Ti-based implants.
\end{abstract}

Key Words: Anti-inflammatory effect, Anti-microbial activity, MC3T3-E1 osteoblastic cell, Rosmarinic acid, Titanium

\section{Introduction}

Titanium (Ti) and some of its alloys are strong and have high biocompatibility, thus, they are widely used in dentistry, in dental implants ${ }^{1)}$. Although the success rate of dental implants is high, failure may occur due to the cytotoxicity of ions from implant materials, periodontitis and peri-implantitis (PI) caused by oral microorganisms, local bone volume reduction, and delayed wound healing ${ }^{1,2)}$. Various studies have indicated that in successful dental implants there is an increase in the osseointegration between $\mathrm{Ti}$ and living bone tissue through adhesion, differentiation, and mineralization of osteoblasts on the $\mathrm{Ti}$ surface, and a reduction the differentiation and activity of osteoclasts. These studies have also examined fluoride treatment ${ }^{3)}$, biological material coatings, such as transforming 
growth factor- $\beta 1$ and type I collagen ${ }^{1)}$, and the formation of nanoscale roughness on the Ti surface ${ }^{4)}$. However, for a successful dental implant, it is necessary to not only control and alleviate the inflammatory reaction around the implant also control the oral microorganisms that cause inflammation. A variety of microorganisms inhibits a dental plaque, and many bacterial species and fungi that cause dental caries and periodontal diseases have been isolated from $\mathrm{it}^{5}$. Colonized periodontal disease-causing bacteria such as Prevotella intermedia, Porphylomonas gingivalis, and Aggregatibacter actinomycetemcomitans which can cause PI, depending on the immunity of the host $^{5,6)}$, Have been observed in a healthy peri-implant sulcus. When dental implants are present in the oral cavity, there is a risk of infection from these bacteria, leading to a failure of the dental implant ${ }^{6}$. Peri-implant mucositis (PIM) and PI frequently occur on the surface and areas surrounding the dental implants ${ }^{7)}$. PIM appears only in gingival tissues around dental implants, whereas PI is characterized by periodontal tissue destruction and alveolar bone resorption ${ }^{7}$. PI is an inflammatory disease caused by infections induced by an imbalance between the host's immune response and an increase in pathogenic periodontal disease-causing bacteria after the osseointegration of dental implants ${ }^{5,7,8)}$. Streptococcus spp., Aggregatibacter spp., Actinomyces spp., and Fusobacterium spp. Have been isolated at sites where PI occurs ${ }^{9,10}$. Many clinical studies have also reported that PI is one of the major causes of implant loss ${ }^{7,11}$.

Plants have long been used in traditional medicines for the control of various diseases and the development of new drugs. Plant-derived therapeutic substances have been used for the prevention and treatment of diseases because they have fewer side effects and various biological activities $^{12)}$. Rosmarinic acid (RA, $\alpha$-o-caffeoyl-3,4dihydroxyphenyl-lactic acid) is a natural polyphenolic compound that is extracted from Perilla frutescens which is widely cultivated for food in Korea, and Lamiaceae herbs, such as sage, basil, and mint ${ }^{13)}$. RA $\mathrm{j}=$ has been shown to not only have anti-inflammatory activity through the inhibition of nuclear factor kappa B (NF-kB) production in various cells ${ }^{13)}$, but also anti-oxidative, anti-inflammatory, anti-mutagen, anti-bacterial and anti-viral activities ${ }^{14}$. On the other hand, unlike other polyphenolic compounds that show weak antimicrobial activity against oral bacteria, RA has been reported to have no microbial activity in oral microorganism ${ }^{8)}$. The various studies on the antimicrobial activities of RA against oral microorganisms causing oral diseases, including PI, are insufficient, and there are no studies on the antiinflammatory effect of RA in the lipopolysaccharide (LPS)-stimulated osteoblasts on the Ti surface to enable the elucidation of its potential for the regulation of PI.

The purpose of this study was to investigate the antimicrobial activity of RA against oral microorganisms and the anti-inflammatory effect of RA on LPS-stimulated MC3T3-E1 osteoblastic cells on the Ti surface during osseointegration, and to confirm the possibility of using RA as a safe natural substance for the control of PI in Ti-based dental implants.

\section{Materials and Methods}

\section{Microbial strains}

Microbial strains to confirm the antimicrobial activity of RA against oral microorganisms were purchased from the Korea Microbial Conservation Center (KCCM) and the Gene Bank (KCTC) and used in the experiment (Table 1). S. mutans was cultured in Brain Heart Infusion (MB cell Ltd., Seoul, Korea) agar and broth, $A$. actinomycetemcomitans in MRS (MB cell Ltd.) agar and broth, and E. coli in Luria Bertani (MB cell Ltd.) agar and

Table 1. Microbial Strains for the Disk Diffusion Test

\begin{tabular}{llll}
\hline \multicolumn{1}{c}{ Microorganism } & \multicolumn{1}{c}{ Strain } & Aero condition & Kind \\
\hline Streptococcus mutans & KCCM 40105 & Facultative anaerobic & Bacteria \\
Aggregatibacter actinomycetemcomitans & KCTC 2581 & Microaerophilic & Bacteria \\
Escherichia coli & KCTC 1039 & Aerobic & Bacteria \\
Candida albicans & KCCM 11282 & Aerobic & Fungus \\
\hline
\end{tabular}


broth. The fungus, $C$. albicans was cultured in potato dextrose agar (MB cell Ltd.) and broth (MB cell Ltd.) and used in the experiment.

\section{Disk diffusion test}

According to the method standardized by Bauer et al. ${ }^{15)}$, microbial strains were incubated from colonies for 24 hours, diluted with sterilized saline solution to $5 \times 10^{6}$ $\mathrm{CFU} / \mathrm{ml}$, and then coated with $100 \mu \mathrm{l}$ on agar medium prepared in a petri dish. Distilled water and $20 \mu$ of RA of each concentration were absorbed onto sterilized paper discs ( $\phi 6$ mm; Advantec Toyo Kaisha Ltd., Tokyo, Japan), and the dried paper discs were placed on agar plates coated with microbial strains, and incubated for 24 hours in an incubator at $36.5^{\circ} \mathrm{C}$, the clear zones were then measured. Ampicillin (10 IU; Oxoid Ltd., Hampshire, United Kingdom) and penicillin G (10 $\mu$; Oxoid Ltd.) antibiotic discs were used as positive controls for RA.

\section{Cell culture and Ti disc}

The MC3T3 E1 osteoblastic cell line derived from mouse calvaria was maintained in Alpha-modified Eagle's medium ( $\alpha$-MEM) containing 10\% (v/v) fetal bovine serum (FBS) and $1 \%(\mathrm{v} / \mathrm{v})$ antibiotic antimycotic solution (WelGENE Inc., Daegu, Korea). The cells were transferred onto the $\mathrm{Ti}$ disc surface and replaced with $\alpha$-MEM medium containing 5\% (v/v) FBS, $10 \mathrm{mM} \beta$-glycerol phosphate, and $50 \mu \mathrm{g} / \mathrm{ml}$ ascorbic acid, and cultured in a $\mathrm{CO} 2$ incubator at $37^{\circ} \mathrm{C}$. According to the method of Jeong et al. ${ }^{16)}$, polished pure Ti discs with diameters of 15,20 , and $48 \mathrm{~mm}$ of $2 \mathrm{~mm}$ were used in the experiment.

\section{LPS and RA treatment}

The medium for cells on the Ti disc was replaced with fresh medium with or without $14 \mu \mathrm{g} / \mathrm{ml}$ of RA before LPS treatment. After 1 hour, $100 \mathrm{ng} / \mathrm{ml}$ of LPS (E. coli serotype 055:B5; cat. No. L2880; Sigma-Aldrich, Chemical Co., St. Louis, MO, USA) was added to the medium. Cells treated with LPS or LPS/RA were cultured according to the set time for the experiment and used in the experiment, and the control was maintained under the same culture conditions.

\section{Measurement of $\mathrm{NO}$ and $\mathrm{PGE}_{2}$}

NO was extracted by processing according to the manufacturer's method using a commercial NO assay kit (R\&D Systems, Mineapolis, MN, USA), and measured at $540 \mathrm{~nm}$ absorbance using an enzyme-linked immunosorbent assay (ELISA) reader (Molecular Devices; Sunnyvale, $\mathrm{CA}, \mathrm{USA}) . \mathrm{PGE}_{2}$ concentration was measured with an ELISA reader at $490 \mathrm{~nm}$ absorbance after treatment according to the manufacturer's method using a $\mathrm{PGE}_{2}$ ELISA kit (R\&D Systems).

\section{RNA isolation and reverse transcription polymerase chain reaction (RT-PCR)}

Total RNA was extracted by processing according to the manufacturer's method using RiboEXTM reagent (GeneAll, Seoul, Korea). Complementary DNA (cDNA) was synthesized using $1 \mu \mathrm{g}$ of isolated total RNA using RT Premix (GeNet Bio, Daejeon, Korea). PCR was performed using a thermocycler (Takara Bio Inc., Shiga, Japan) after adding $1 \mu$ of cDNA and the gene-specific primers to the PCR premix (GeneAll) to amplify tumor necrosis factor (TNF- $\alpha$ ) and interleukin (IL)- $1 \beta$ genes from cDNA. The PCR products were electrophoresed on $1.5 \%$ agarose gel (Takara Bio Inc.) buffered with $0.5 \times$ Tris-borateethylenediaminetetraacetic acid, stained with ethidium bromide (Sigma-Aldrich), and then visualized with a Gel-Doc System (BioRad Laboratories, Inc., Hercules, CA, USA). The intensity of the band was measured using a Science Lab Image Gauge (FUJI FILM, Tokyo, Japan). Glyceraldehyde 3-phosphate dehydrogenase (GAPDH) was used as a control. The PCR primers were as follows: TNF- $\alpha$ forward, 5'-TCT CAT CAG TTC TAT GGC CC-3' and reverse, 5-GGG AGT AGA CAA GGT ACA AC-3'; IL-1 $\beta$ forward: 5'-TCT GTG ACT CGT GGG ATG AT-3' and reverse, 5'-TGT CGT TGC TTG TCT CTC TCC T-3'; GAPDH forward, 5'-CCA TGG AGA AGG CTG GG-3 and reverse: 5'-CAA AGT TGT CAT GGA TGA CC-3' (Bioneer Corp., Ltd., Daejeon, Korea) The annealing temperature for each primer and number of cycles were as follows: TNF- $\alpha, 58^{\circ} \mathrm{C}$ and 35 cycles; IL- $1 \beta, 59^{\circ} \mathrm{C}$ and 36 cycles; and GAPDH, $60^{\circ} \mathrm{C}$ and 30 cycles. 


\section{Protein extraction and western blot analysis}

Total protein was extracted from MC3T3-E1 cells using an NP-40 lysis buffer, and protein concentration was determined using the Bradford Protein assay kit (Bio-Rad Laboratories, Inc.). The protein samples (30 $\mu \mathrm{g} / \mathrm{lane})$ were electrophoresed on $10 \%$ SDS-polyacrylamide gel and transferred onto polyvinylidene difluoride membranes (Merck Millipore, Darmstadt, Germany). The membranes were blotted with primary antibodies at $4^{\circ} \mathrm{C}$ overnight, i.e., 1:1,000 of anti-rabbit TNF- $\alpha$ (Abcam, Inc., Cambridge, MA, USA), IL-1 $\beta$ antibody (Abcam, Inc.), and 1:2,500 anti-mouse $\beta$-actin antibody (Santa Cruz Biotechnology Inc., Santa Cruz, CA, USA). After washing, the membrane was incubated with 1:5,000 horseradish peroxidaseconjugated secondary antibody (goat anti-rabbit or mouse-IgG, Santa Cruz Biotechnology Inc.) for 1 hour. The development was performed using an X-ray film (FUJI FILM, Tokyo, Japan) after detection using an ECL solution (Merck Millipore). The intensity of bands was measured using a Science Lab Image Gauge (FUJI FILM, Tokyo, Japan). $\beta$-Actin was used as a control.

\section{Statistical analysis}

All the experiments were carried out in triplicate. All the data were expressed as means \pm standard deviations. The statistical analysis was performed using SPSS 16.0 (SPSS Inc., Chicago, IL, USA). Statistically significant differences were determined using the Student's t-test. The significance level for determining statistical significance was set at 0.05 .

\section{Results}

\section{Antimicrobial activity of RA against oral microorganisms}

The results of the disk diffusion test to confirm the antimicrobial activity of RA against oral microorganisms are presented in Table 2 and illustrated in Fig. 1. RA showed a weak antimicrobial effect on $S$. mutans and $E$. coli, and the antimicrobial activity of RA increased with increasing concentration. RA did not show any antibacterial activity against the bacterium $A$. actinomycetemcomitans and the fungus $C$. albicans. These results show that RA has the potential to control some oral bacteria.

Table 2. Anti-Microbial Activity of Rosmarinic Acid (RA) and Antibiotics by the Disk Diffusion Test

\begin{tabular}{|c|c|c|c|c|c|c|c|c|}
\hline \multirow{2}{*}{ Microorganism } & \multicolumn{6}{|c|}{$\mathrm{RA}(\mu \mathrm{g})$} & \multirow{2}{*}{$\begin{array}{l}\text { Ampicillin } \\
\text { (10 IU) }\end{array}$} & \multirow{2}{*}{$\begin{array}{l}\text { Penicillin } \mathrm{G} \\
\quad(10 \mathrm{mcg})\end{array}$} \\
\hline & 0 & 18 & 36 & 54 & 72 & 90 & & \\
\hline Streptococcus mutans & - & - & - & - & + & + & +++ & ++ \\
\hline Aggregatibacter actinomycetemcomitans & - & - & - & - & - & - & ++ & ++ \\
\hline Escherichia coli & - & - & - & - & - & + & + & + \\
\hline Candida albicans & - & - & - & - & - & - & - & - \\
\hline
\end{tabular}

-: resistrant $(<5 \mathrm{~mm}),+$ : susceptible $(5 \sim 14 \mathrm{~mm}),++$ : more susceptible $(15 \sim 24 \mathrm{~mm}),+++:$ most susceptible $(>25 \mathrm{~mm})$.
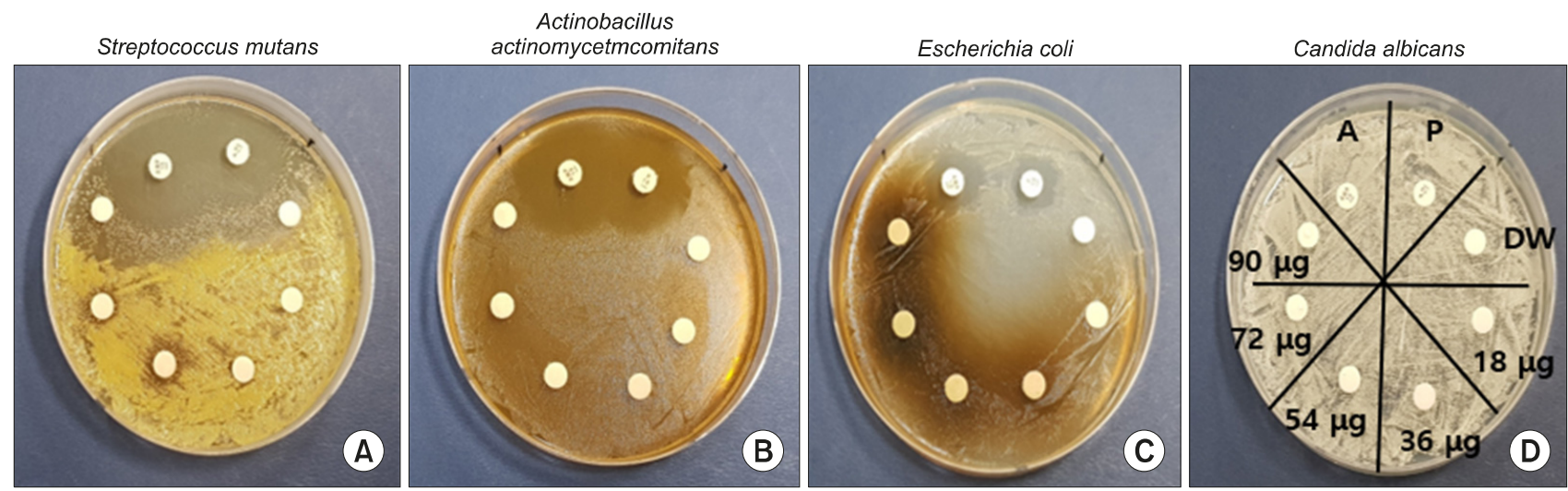

Fig. 1. Anti-microbial activity of rosmarinic acid against oral microorganisms. A: ampicillin, P: penicillin G, DW: distilled water. 
2. Effect of RA on LPS-induced production of pro-inflammatory mediators in MC3T3-E1 osteoblastic cells on the Ti disc surface

The amount of NO production was compared between the group treated with LPS alone (LPS/MC3T3-E1) and the group treated with LPS and RA (LPS/RA/MC3T3-E1).

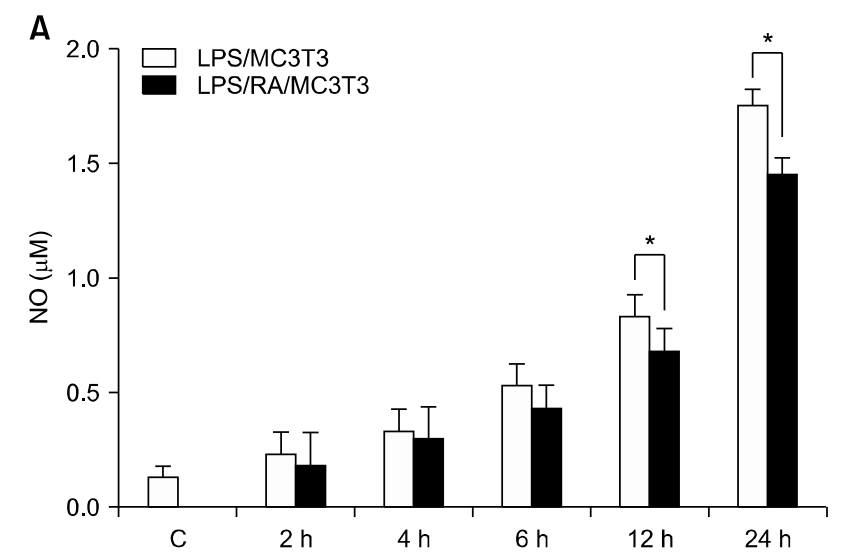

The amount of NO produced in LPS/RA/MC3T3-E1 at all time points was decreased compared to that in LPS/ MC3T3-E1, and the amount of NO at 12 and 24 hours decreased significantly (Fig. 2A). The amount of $\mathrm{PGE}_{2}$ produced was significantly lower in LPS/RA/MC3T3-E1 than in LPS/MC3T3-E1, except at 2 hours (Fig. 2B). In

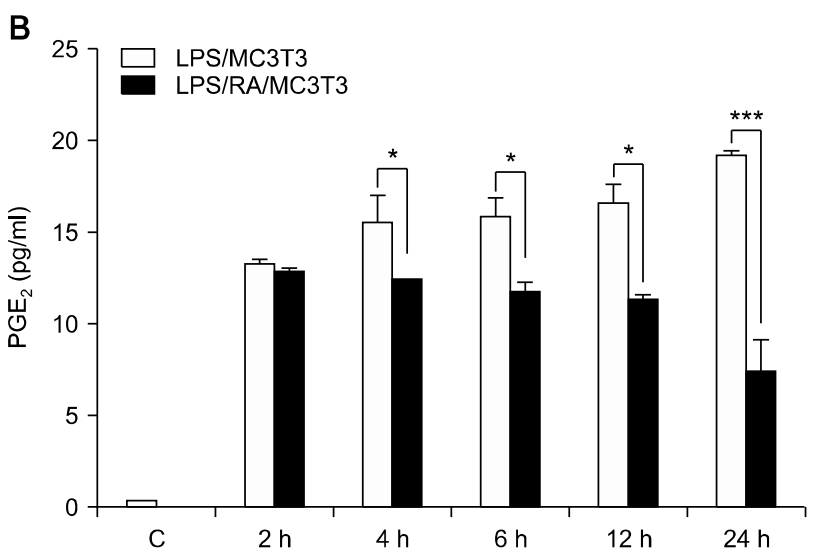

Fig. 2. Effects of rosmarinic acid (RA) on production of pro-inflammatory mediators in MC3T3-E1 osteoblastic cells on a titanium (Ti) surface. RA significantly reduced production of $\mathrm{NO}$ (A) and $\mathrm{PGE}_{2}$ (B) in LPS-stimulated MC3T3-E1 osteoblastic cells on a Ti surface $\left({ }^{*}<<0.05 ;{ }^{* * *} p<0.001\right)$. NO: nitric oxide, LPS: lipopolysaccharide, C: control.

A
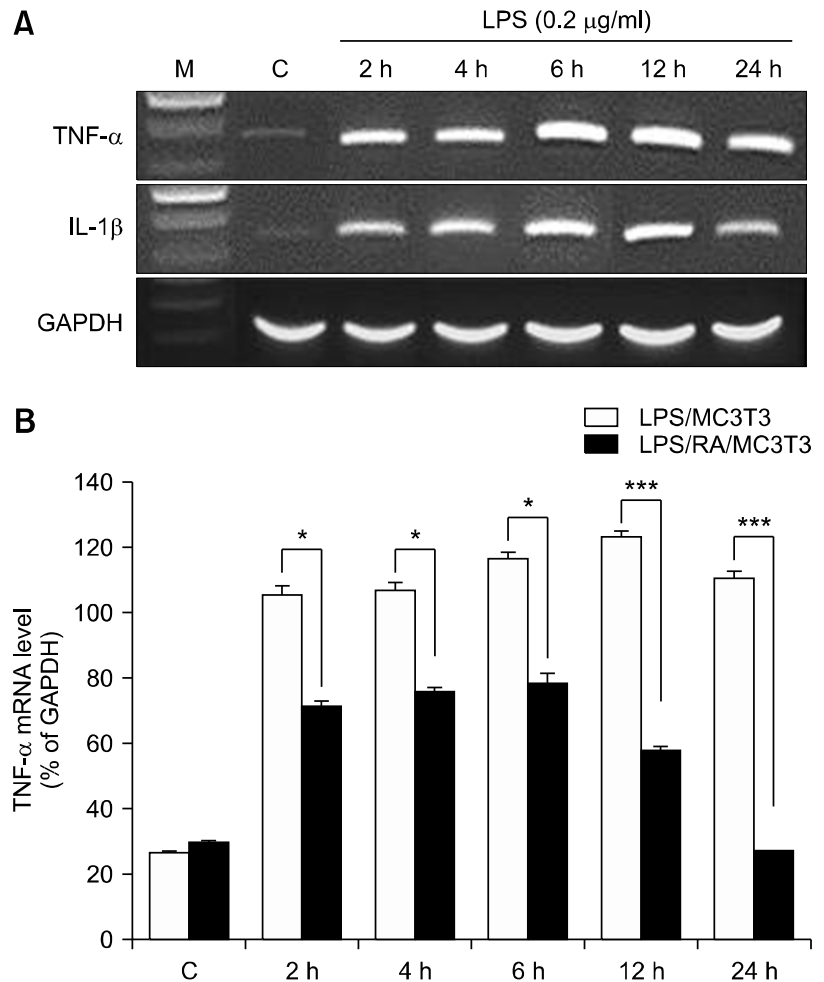

C

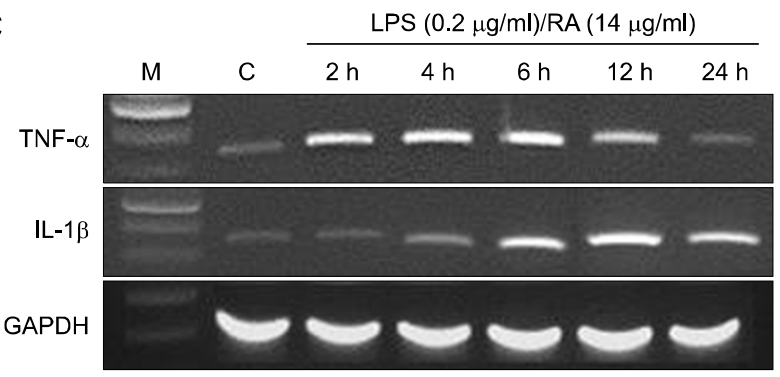

D

PS/MC3T3

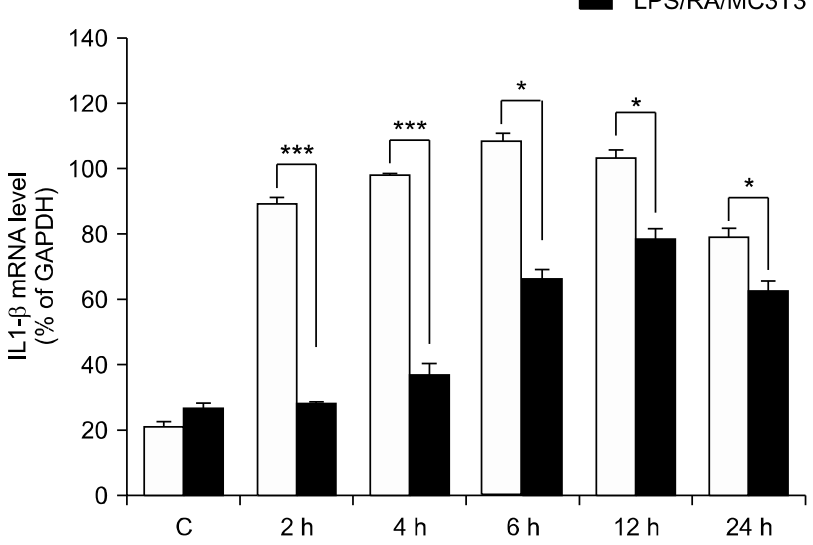

Fig. 3. Effects of rosmarinic acid (RA) on TNF- $\alpha$ and IL1- $\beta$ mRNA expression in MC3T3-E1 osteoblastic cells on a titanium (Ti) surface. RA significantly reduced the mRNA expression of TNF- $\alpha$ (A, B) and IL1- $\beta$ (C, D) in lipopolysaccharide (LPS) -stimulated MC3T3-E1 osteoblastic cells on a Ti surface $\left({ }^{*} \mathrm{p}<0.05 ;{ }^{* *} \mathrm{p}<0.001\right)$. M: maker, C: control. 
particular, the production of $\mathrm{PGE}_{2}$ at 24 hours in LPS/RA/MC3T3-E1 showed a large decrease of 2.6 times compared to that of LPS/MC3T3-E1. Therefore, RA significantly reduced the production of $\mathrm{NO}$ and $\mathrm{PGE}_{2}$, a pro-inflammatory mediator, in LPS-stimulated MC3T3-E1 osteoblastic cells on the Ti surface, and this result shows that RA has the potential to control inflammatory conditions.

\section{Effect of RA on LPS-induced productions of pro-inflammatory cytokines in MC3T3-E1 osteoblastic cells on Ti disc surface}

The mRNA and protein expression of TNF- $\alpha$ and IL1- $\beta$ in LPS/MC3T3-E1 and LPS/RA/MC3T3-E1 on the Ti surface are shown in Fig. 3 and 4. The mRNA expression of TNF- $\alpha$ on the Ti surface was significantly decreased in LPS/RA/MC3T3-E1 at all time points than in LPS/ MC3T3-E1, and decreased by 2 and 4 times at 12 and 24 hours, respectively (Fig. 3A, 3B). The protein expression of TNF- $\alpha$ was also significantly decreased at all time points of LPS/RA/MC3T3-E1 than in LPS/MC3T3-E1

A

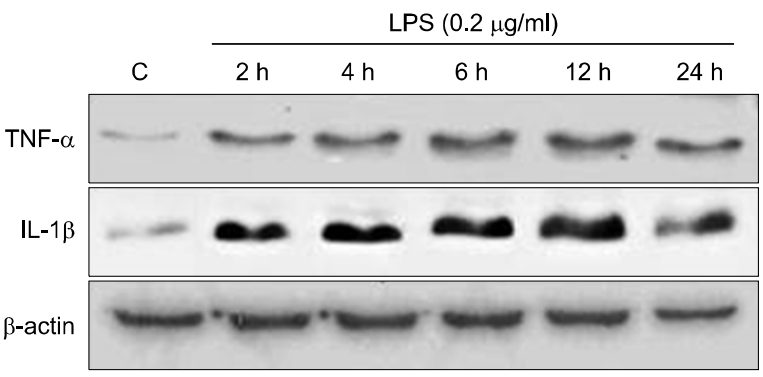

B

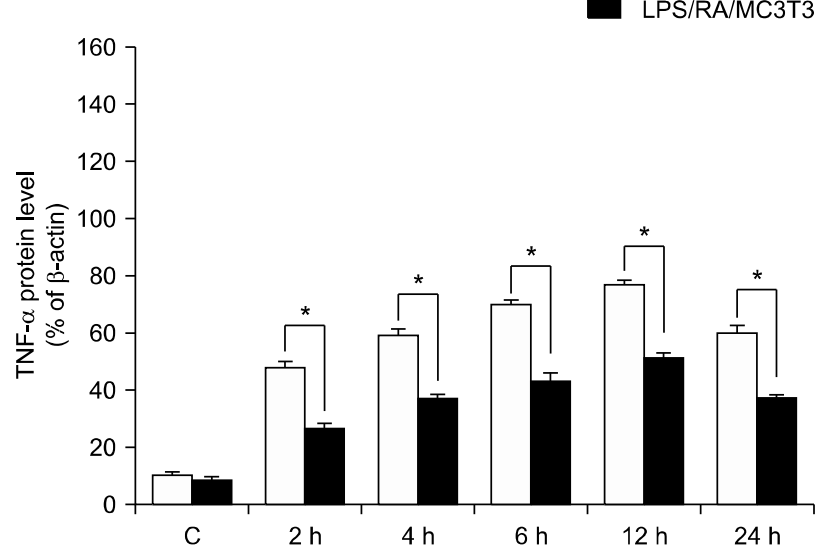

cells (Fig. 4A, 4B). In comparison with LPS/MC3T3-E1 cells, the IL1- $\beta$ mRNA expression of LPS/RA/MC3T3-E1 cells was significantly decreased at all time points, and 3.2 and 2.7 times decreased at 2 and 4 hours, respectively (Fig. 3C, 3D). IL1- $\beta$ protein expression was also significantly decreased in LPS/RA/MC3T3-E1 cells (Fig. 4C, 4D). From the above results, in LPS-stimulated MC3T3-E1 osteoblastic cells on the Ti surface, RA significantly reduced the mRNA and protein expression of TNF- $\alpha$ and IL1- $\beta$, pro-inflammatory cytokines that play an important role in the initial inflammatory response. This indicates that RA is effective in relieving LPS-induced inflammation.

\section{Discussion}

Periodontal disease is an inflammatory disease caused by oral microbial infection, which induces destruction of periodontal tissue and alveolar bone, resulting in tooth loss ${ }^{9)}$. PI that occurs after dental implant treatment is also an inflammatory disease caused by infection with oral

C

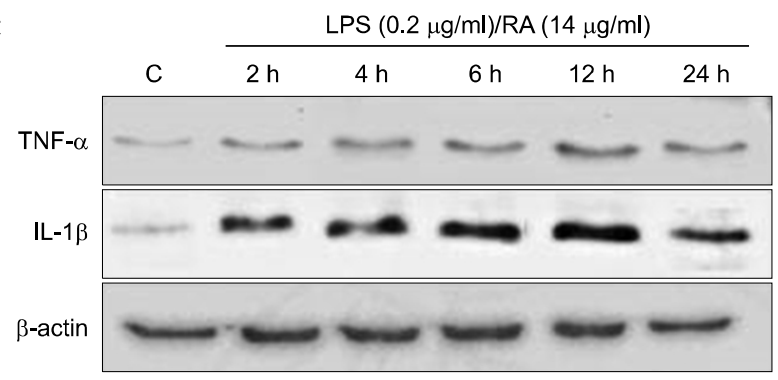

D LPS/MC3T3

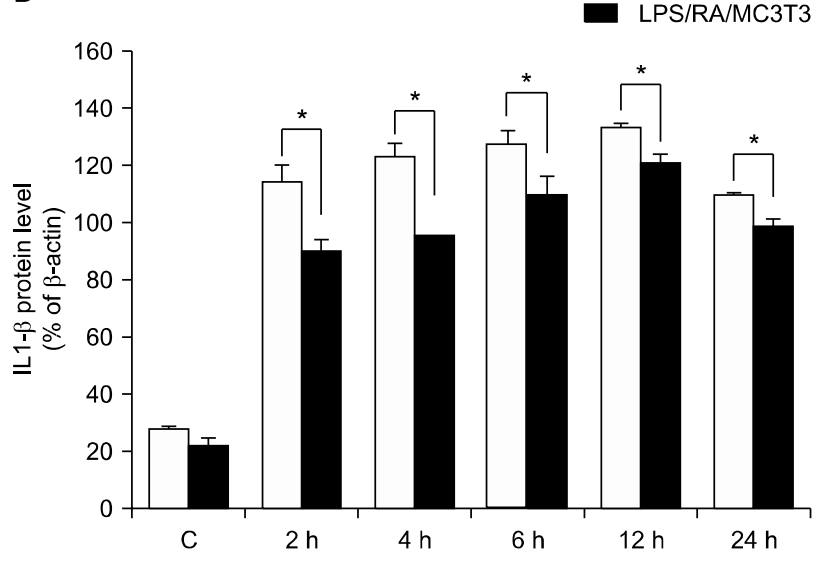

Fig. 4. Effects of rosmarinic acid (RA) on TNF- $\alpha$ and IL1- $\beta$ protein expression in MC3T3-E1 osteoblastic cells on a titanium (Ti) surface. RA significantly reduced the protein expression of TNF- $\alpha$ (A, B) and IL1- $\beta$ (C, D) in lipopolysaccharide (LPS) -stimulated MC3T3-E1 osteoblastic cells on a Ti surface $\left({ }^{*} p<0.05\right)$. 
bacteria, initiated by an imbalance between an increase in oral pathogenic bacteria and the host's response ${ }^{6-8)}$, and is characterized by the destruction of periodontal tissue and alveolar bone resorption ${ }^{7)}$. Pain and loss of physical function due to PI eventually induces the removal of the implant, leading to implant failure ${ }^{7,11)}$. LPS, which is present in the outer membrane of gram-negative bacteria, is a pathogenic endotoxin that induces periodontal tissue destruction and bone resorption, and is commonly used to induce inflammatory conditions to evaluate the effects of drugs $^{17)}$. S. mutans causes dental caries by synthesizing glucan from sucrose by producing glucosyltransferrase ${ }^{18,19)}$. E. coli is known to account for $15 \%$ of the oral flora, is a gram-negative bacillus that lives in the intestine and is an important contamination indicator for hygiene ${ }^{20)}$. E. coli is a major causative bacterium of hospital infection and causes gastrointestinal diseases showing symptoms of food poisoning and diarrhea ${ }^{21,22)}$. Most of them live transiently in the oral cavity, but their presence increases with age and affects saliva secretion, leading to dry mouth $^{20)}$. A. actinomycetemcomitans causes aggressive periodontitis and is a highly permeable bacterium that can penetrate the epithelial and vascular endothelial cells ${ }^{23)}$. Their strong penetratve ability can act as an important virulence factor in the spread of bacteria to periodontal tissues and induce inflammation, as well as have a relationship with alveolar bone absorption ${ }^{23,24)}$. C. albicans, a representative fungus living in the oral cavity, is generally non-pathogenic, but attaches to the oral cavity and dentures of patients with weakened immunity or poor oral hygiene, causing oral candidiasis or opportunistic infections ${ }^{25,26)}$. In previous studies, RA did not show antibacterial activity against oral pathogenic bacteria ${ }^{8)}$, however, in this study, RA showed a weak anti-bacterial effect on some of the oral bacteria, but not on the fungus, C. albicans (Table 2, Fig. 1). These results were similar as those for other polyphenolic compounds ${ }^{8)}$. Therefore, RA has a weak antibacterial effect on some of the bacteria living in the oral cavity and has the potential to be utilized as a safe substance derived from natural products for the prevention and control of periodontitis and PI.

The transcription factor, NF- $\kappa \mathrm{B}$ is translocated to the nucleus by inflammatory stimuli such as LPS, and regulates DNA transcription and production of various pro-inflammatory genes such as inducible NO synthase (iNOS), cyclooxygenase-2 (COX-2), IL-1 $\beta$, TNF- $\alpha^{27,28)}$. iNOS and COX-2 are responsible for the production of $\mathrm{NO}$ and $\mathrm{PGE}_{2}$, respectively. Bone cells stimulated by LPS increase iNOS gene expression and induce the release of overproduced $\mathrm{NO}^{27)}$. NO not only inhibits osteoblast growth and increases apoptosis, but also regulates osteoclast activity and recruitment ${ }^{27)}$. $\mathrm{PGE}_{2}$, catalyzed by COX-2 during the inflammatory reaction, causes a decrease in the bone alkaline phosphatase activity and induces osteoclast differentiation in the stem cells ${ }^{17,27)}$. TNF- $\alpha$ and IL-1 are both osteoclastogenic factors and bone resorption factors ${ }^{29)}$. TNF- $\alpha$ and IL-1 $\beta$, produced through NF- $\kappa \mathrm{B}$ signaling inhibit osteoblastic bone formation and induce an increase in the expression of the receptor activator of NF- $\mathrm{KB}$ ligand (RANKL), and the secreted RANKL induces the formation of osteoclasts and plays an important role in the initiation and acceleration of alveolar bone resorption and periodontal disease ${ }^{23,24)}$. This means that the control of pro-inflammatory mediators and cytokines can also control osteoclast formation and bone resorption. This study showed that RA reduced the

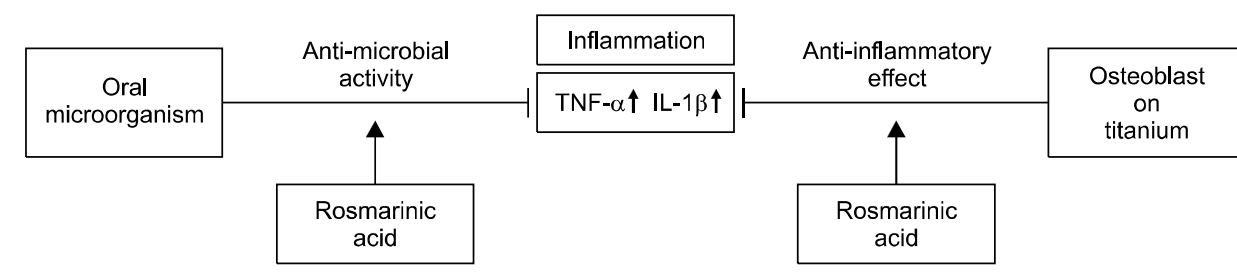

Fig. 5. Schematic diagram of antioral microbial activity and anti-inflammatory effects of rosmarinic acid in MC3T3-E1 osteoblastic cells on a titanium (Ti) surface. 
production of pro-inflammatory mediators, $\mathrm{NO}$ and $\mathrm{PGE}_{2}$ and pro-inflammatory cytokines, TNF- $\alpha$ and IL- $1 \beta$ in LPS-stimulated MC3T3-E1 osteoblastic cells on the Ti surface at the protein and mRNA levels (Fig. $2 \sim 4$ ). This implies that RA plays a role at the transcriptional level.

Therefore, RA not only has anti-oral microbial activity, but also anti-inflammatory effects in LPS-stimulated MC3T3-E1 osteoblasts (Fig. 5). It can be used as a safe functional substance derived from natural products for the prevention and control of PI for successful Ti-based implants.

\section{Notes}

\section{Conflict of interest}

No potential conflict of interest relevant to this article was reported.

\section{Ethical approval}

This article is not necessary for IRB screening.

\section{Author contributions}

Conceptualization: Moon-Jin Jeong, Soon-Jeong Jeong. Data acquisition: Do-Seon Lim, Kyungwon Heo. Formal analysis: Do-Seon Lim, Kyungwon Heo. Funding: Soon-Jeong Jeong. Supervision: Soon-Jeong Jeong. Writing-original draft: Soon-Jeong Jeong. Writing-review \& editing: Moon-Jin Jeong, Soon-Jeong Jeong.

\section{ORCID}

Moon-Jin Jeong, https://orcid.org/0000-0002-5547-898X

Do-Seon Lim, https://orcid.org/0000-0003-4602-3323

Kyungwon Heo, https://orcid.org/0000-0003-0214-2216

Soon-Jeong Jeong, https://orcid.org/0000-0002-8959-4663

\section{Acknowledgements}

This research was supported by Basic Science Research Program through the National Research Foundation of Korea (NRF) Grant funded by the Korea government (2017R1D1A1B03033263).

\section{References}

1. Jeong SJ, Jeong MJ: Effect of thymosin beta4 on the differentiation and mineralization of MC3T3-E1 cell on a titanium surface. J Nanosci Nanotechnol 16: 1979-1983, 2016. https://doi.org/10.1166/jnn.2016.11928

2. Choi BD, Lee SY, Jeong SJ, et al.: Secretory leukocyte protease inhibitor promotes differentiation and mineralization of MC3T3-E1 preosteoblasts on a titanium surface. Mol Med Rep 14: 1241-1246, 2016. https://doi.org/10.3892/mmr.2016.5381

3. Kokubo T, Yamaguchi S: Bioactive Ti metal and its alloys prepared by chemical treatments: state-of-the-art and future trends. Adv Eng Mater 12: B579-B591, 2010. https://doi.org/10.1002/adem.201080087

4. Khang D, Choi J, Im YM, et al.: Role of subnano-, nano- and submicron-surface features on osteoblast differentiation of bone marrow mesenchymal stem cells. Biomaterials 33: 5997-6007, 2012. https://doi.org/10.1016/j.biomaterials.2012.05.005

5. Yamamoto H, Ogawa T: Antimicrobial activity of perilla seed polyphenols against oral pathogenic bacteria. Biosci Biotechnol Biochem 66: 921-924, 2002. https://doi.org/10.1271/bbb.66.921

6. Pokrowiecki R, Mielczarek A, Zaręba T, Tyski S: Oral microbiome and peri-implant diseases: where are we now? Ther Clin Risk Manag 13: 1529-1542, 2017. https://doi.org/10.2147/TCRM.S139795

7. Wachi T, Shuto T, Shinohara Y, Matono Y, Makihira S: Release of titanium ions from an implant surface and their effect on cytokine production related to alveolar bone resorption. Toxicology 327: 1-9, 2015. https://doi.org/10.1016/j.tox.2014.10.016

8. Bernardes WA, Lucarini R, Tozatti MG, et al: Antimicrobial activity of Rosmarinus officinalis against oral pathogens: relevance of carnosic acid and carnosol. Chem Biodivers 7: 1835-1840, 2010. https://doi.org/10.1002/cbdv.200900301

9. Yeh HC, Lu JJ, Chang SC, Ge MC: Identification of microbiota in peri-implantitis pockets by matrix-assisted laser desorption/ionization time-of-flight mass spectrometry. Sci Rep 9: 774, 2019 https://doi.org/10.1038/s41598-018-37450-5

10. Eswar P, Devaraj CG, Agarwal P: Anti-microbial activity of Tulsi \{Ocimum sanctum (Linn.)\} extract on a periodontal pathogen in human dental plaque: an invitro study. J Clin Diagn Res 10: ZC53-ZC56, 2016. 
https://doi.org/10.7860/JCDR/2016/16214.7468

11. Brett E, Flacco J, Blackshear C, Longaker MT, Wan DC: Biomimetics of bone implants: the regenerative road. Biores Open Access 6: 1-6, 2017.

https://doi.org/10.1089/biores.2016.0044

12. Kim MY, Bo HH, Choi EO, et al.: Induction of apoptosis by Citrus unshiu peel in human breast cancer MCF-7 cells: involvement of ROS-dependent activation of AMPK. Biol Pharm Bull 41: 713-721, 2018. https://doi.org/10.1248/bpb.b17-00898

13. Kim HK, Lee JJ, Lee JS, Park YM, Yoon TR: Rosmarinic acid down-regulates the LPS-induced production of monocyte chemoattractant protein-1 (MCP-1) and macrophage inflammatory protein-1alpha (MIP-1alpha) via the MAPK pathway in bone-marrow derived dendritic cells. Mol Cells 26: 583-589, 2008.

14. Moon DO, Kim MO, Lee JD, Choi YH, Kim GY: Rosmarinic acid sensitizes cell death through suppression of TNFalpha-induced NF-kappaB activation and ROS generation in human leukemia U937 cells. Cancer Lett 288: 183-191, 2010. https://doi.org/10.1016/j.canlet.2009.06.033

15. Bauer AW, Kirby WM, Sherris JC, Turck M: Antibiotic susceptibility testing by a standardized single disk method. Am J Clin Pathol 45: 493-496, 1996. https://doi.org/10.1093/ajcp/45.4_ts.493

16. Jeong SJ, Wang G, Choi BD, et al.: Secretory leukocyte protease inhibitor (SLPI) increases focal adhesion in MC3T3 osteoblast on titanium surface. J Nanosci Nanotechnol 15: 200-204, 2015. https://doi.org/10.1166/jnn.2015.8383

17. Kwon DH, Cha HJ, Choi EO, et al.: Schisandrin A suppresses lipopolysaccharide-induced inflammation and oxidative stress in RAW 264.7 macrophages by suppressing the NF- $\kappa B$, MAPKs and PI3K/Akt pathways and activating Nrf2/HO-1 signaling. Int J Mol Med 41: 264-274, 2018.

https://doi.org/10.3892/ijmm.2017.3209

18. Min YK, Jeon JK, Kim SG, Chang KW: Inhibitory effects of Schizandra chinensis extracts on the growth and adsorption to saliva- coated HA beads of some oral bacteria. J Korean Acad Dent Health 25: 165-183, 2001.

19. Heo NS, Choi HJ, Hwang SM, Choi YW, Lee YG, Joo WH: Antimicrobial and anti-oral malodor efficacy of Schizandra chinensis extracts against oral pathogens. J Life Sci 23:
443-447, 2013.

https://doi.org/10.5352/JLS.2013.23.3.443

20. Feng P, Weagant SD, Grant MA, Burkhardt W: BAM 4: enumeration of Escherichia coli and the coliform bacteria. 8th ed. U.S. Food and Drug Administration, Silver Spring, 2002.

21. Kim YB, Kim MJ, Park GS: Studies on the bfp gene, adherence to HEp-2 cells and serotyping of Escherichia coli isolated from urine. J Korean Soc Microbiol 33: 77-87, 1998.

22. Kim YB, Park JH, Kim MJ: Hydrophobicity test and DNA probe hybridization assay in the detection of enterotoxigenic Escherichia coli. J Korean Soc Microbiol 32: 15-25, 1997.

23. Choi HK, Lee YS, Kim MY, Kim KD, Cha JH, Yoo YJ: Induction of osteoclastogenesis-inducing cytokines and invasion by alive Aggregatibacter actinomycetemcomitans in osteoblasts. J Korean Acad Periodontol 37: 553-562, 2007. https://doi.org/10.5051/jkape.2007.37.3.553

24. Na HS, Jeong SY, Park MH, Kim S, Chung J: Nuclear factor- $\kappa \mathrm{B}$ dependent induction of TNF- $\alpha$ and IL- $1 \beta$ by the Aggregatibacter actinomycetemcomitans Lipopolysaccharide in RAW 264.7 cells. Int J Oral Biol 39: 15-22, 2014. https://doi.org/10.11620/IJOB.2014.39.1.015

25. Jeon HD, An KS, Park CW, Lee HS, Kim SG: Relationship between adherence of Candida albicans to human buccal epithelial cell in vitro and their virulence. J Hanyang Med 2: 855-876, 1987.

26. Kim MJ, Shin SW, Lee JY. In vitro study on the adherence and penetration of Candida albicans into denture soft lining materials. J Korean Acad Prosthodont 44: 466-476, 2006.

27. Kang HJ, Jeong JS, Park NJ, et al.: An ethanol extract of Aster yomena (Kitam.) Honda inhibits lipopolysaccharideinduced inflammatory responses in murine RAW 264.7 macrophages. Biosci Trends 11: 85-94, 2017. https://doi.org/10.5582/bst.2016.01217

28. Jeong SJ, Choi BD, Lee HY, et al.: $660 \mathrm{~nm}$ red LED induces secretory leukocyte protease inhibitor (SLPI) in lipopolysaccharide-stimulated RAW264.7 cell. J Nanosci Nanotechnol 15: 5610-5616, 2015. https://doi.org/10.1166/jnn.2015.10465

29. Lee SY, Nho TH, Choi BD, Jeong SJ, Lim DS, Jeong MJ: Secretory leukocyte protease inhibitor reduces inflammation and alveolar bone resorption in LPS-induced periodontitis in rats and in MC3T3-E1 preosteoblasts. Anim Cells Syst 20: 344-352, 2016. https://doi.org/10.1080/19768354.2016.1250817 